\title{
Animal models of Huntington's disease: implications in uncovering patho- genic mechanisms and developing therapies ${ }^{1}$
}

\author{
Lin-hui WANG ${ }^{2}$, Zheng-hong QIN ${ }^{3,4}$ \\ Departments of ${ }^{2}$ Physiology and ${ }^{3}$ Pharmacology, Soochow University School of Medicine, Suzhou 215123, China
}

\section{Key words}

Huntington's disease; huntingtin; neurodegeneration; animal models

\footnotetext{
${ }^{1}$ Project supported by the National Natural Science Foundation of China (№ 30370506) and by the Specialized Research Fund for the Doctoral Program of Higher Education (No 20050285017).

${ }^{4}$ Correspondence to Dr Zheng-hong QIN.

$\mathrm{Phn} / \mathrm{Fax}$ 86-512-6588-0406.

E-mail zhqin5@hotmail.com

Received 2006-03-16

Accepted 2006-05-21

doi: $10.1111 /$ j.1745-7245.2006.00410.x
}

\begin{abstract}
Huntington's disease (HD) is an autosomal dominant neurodegenerative disorder, which is caused by an abnormal expansion of Cytosine Adenine Guanine (CAG) trinucleotide repeat in the gene making huntingtin (Htt). Despite intensive research efforts devoted to investigate molecular mechanisms of pathogenesis, effective therapy for this devastating disease is still not available at present. The development of various animal models of $\mathrm{HD}$ has offered alternative approaches in the study of HD molecular pathology. Many HD models, including chemicalinduced models and genetic models, mimic some aspects of HD symptoms and pathology. To date, however, there is no ideal model which replicates all of the essential features of neuropathology and progressive motor and cognitive impairments of human HD. As a result, our understanding of molecular mechanisms of pathogenesis in HD is still limited. A new model is needed in order to uncover the pathogenesis and to develop novel therapies for HD. In this review we discussed usefulness and limitations of various animal and cellular models of $\mathrm{HD}$ in uncovering molecular mechanisms of pathogenesis and developing novel therapies for $\mathrm{HD}$.
\end{abstract}

\section{Introduction}

Huntington's disease (HD) is a devastating, autosomal dominant neurodegenerative disorder caused by a Cytosine Adenine Guanine(CAG) trinucleotide repeat expansion within exon 1 of the huntingtin $(\mathrm{Htt})$ gene $^{[1]}$. This disease is associated with the selective degeneration of striatal GABAergic projection neurons and cortical pyramidal neurons and is characterized by choreiform movements, cognitive deficits and psychiatric disturbances. The genetic mutation underlying HD was discovered in 1993. Normally, the number of CAG-repeats in the polyglutamine (polyQ) tract near the Nterminus of the Htt gene is between 19 and 35. In the diseased state, this number increases to more than 36 repeats. Complete penetration is seen with CAG-repeat lengths of 42 or more ${ }^{[2]}$. This disease affects about 5 out of 100000 people in Western countries. Although the onset of HD symptoms generally occur at the age of 40 or 50 , the disease can start at any time from early childhood to old age, with a mean dura- tion of 15-20 years.

The pathogenesis of HD has not yet been fully understood. Several hypotheses have been proposed to elucidate the mechanisms of HD pathogenesis, including excitotoxicity, oxidative stress, and impaired energy metabo$\operatorname{lism}^{[3]}$, abnormal protein aggregation, transcription dysregulation and abnormal protein interactions ${ }^{[4]}$. Because of incomplete understanding of the mechanisms of HD pathogenesis, treatment to delay the onset or slowdown progression remains unavailable at present. Animal models which closely mimic the neurobiological and clinical symptoms of the disease may provide an alternative approach for the study of HD molecular pathogenesis, the refinement of existing treatments and the development of novel therapies for HD. Therefore, animal models are a crucial part of this rapidly advancing field of $\mathrm{HD}$ research. In this paper, a variety of animal models generated to date are reviewed, and their differences, the implications in uncovering pathogenic mechanisms and developing therapies are discussed. 


\section{Clinical symptoms and neuropathology in HD patients}

There are 3 main groups of symptoms including movement disorder, cognitive impairment and psychiatric disturbance, of which the most characteristic is the choreic movement. Generally, clinical symptoms develop very rapidly after onset and compose a 3-part picture with motor symptoms, characterized by hyperkinesia evolving to hypokinesia. Initially, patients demonstrate personality changes and develop small involuntary movements. Typically, the earliest motor signs are eye movement abnormalities, followed by the progressive appearance of orofacial dyskinesias, involving the head, neck, trunk and arms, before becoming chorea. As the disease progresses, the movement disorder becomes more pronounced. Severity may vary from restlessness with mild, intermittent exaggeration of gesture and expression, fidgeting movements of the hands, unstable, dance-like gait, to a continuous flow of disabling, violent movements. Even though the typical movement disorder is chorea, virtually any type of movement disorder can be seen, including dystonia, rigidity, myoclonus, and athetosis. As the disease progresses, choreiform movements may be reduced in intensity or frequency; the initial hyperkinetic syndrome being progressively replaced by a more hypokinetic syndrome in which bradykinesia, rigidity and dystonia dominate. With the movement disorder, cognitive deficits as well as psychiatric disturbances occur. Cognitive dysfunction includes dementia and difficulties with executive functioning. Psychiatric disturbances most commonly manifest as apathy and depression, but obsessivecompulsive disorder, psychosis, paranoia, and substance abuse also occur. Weight loss is another common feature of the disease. The patients rapidly require constant care and progressively lose their autonomy, dying on average 17 years from the onset of the disease. Death usually results from aspiration pneumonia secondary to dysphagia, or from complications resulting from falls or chronic illness ${ }^{[5]}$.

The juvenile form of HD is caused by CAG-repeat lengths exceeding 60. Clinical manifestations are more severe in presentation and progress more rapidly. Juvenile HD is most often inherited through paternal transmission. The movement disorder tends to be more parkinsonian than the adult form and is characterized by bradykinesia, rigidity, resting tremor and seizure. Juvenile patients have a more severe course of the disease with an average duration of 5 to 20 years $^{[6,7]}$.

HD brains are significantly lighter at death than normal brains. The most striking neuropathological feature of HD is a marked atrophy of the caudate and putamen within the basal ganglia. In addition, the neuronal loss in the striatum is accompanied by pronounced gliosis. The pathology of HD has been classified by Vonsattel et al from grade 0 (no changes) to grade 4 depending on the degree of striatal atrophy (caudate and putamen reduced to a rim of tissue $)^{[8]}$. The striatum is comprised of several neuronal subtypes including medium spiny projection neurons and interneurons. The latter category includes the medium-sized aspiny reduced nicotinamide adenine dinucleotide phosphate (NADPH) diaphorase-positive, neuronal nitric oxide synthase (nNOS)positive neurons and large aspiny cholinergic neurons. Interestingly, many studies have consistently shown that not all striatal cells are equally affected by the degenerative process. HD preferentially affects the GABAergic mediumsized spiny neurons, leaving the other subpopulations of striatal neurons largely unaffected in the early stage ${ }^{[9-13]}$. The factors that render striatal projection neurons more susceptible to damage are unclear. Within the subpopulation of striatal GABAergic medium-sized spiny neurons, not all neurons are similarly affected by HD. A double gradient of striatal degeneration has been described in the HD striatum, one progressing in a dorsolateral to ventral direction and another in a caudo-rostral direction ${ }^{[14]}$.

Although the striatum is the most profoundly affected region in $\mathrm{HD}$, neuronal loss may also occur in the cortex, thalamus, zona reticulata of the substantia nigra, superior olive, lateral tuberal nucleus of the hypothalamus and deep cerebellar nuclei ${ }^{[15-17]}$. Therefore, the changes in the striatum reflect a relatively selective vulnerability to cell death. Interestingly, a common feature to all these areas is that, with the exception of the cortex, they all belong to the basal ganglia circuitry, and as such, are directly or indirectly connected to the striatum. The cerebral cortex is also markedly atrophied in the later stages of the disease. In the cortex, large neurons in layer VI are the most affected, with smaller amounts of degeneration seen in layers III and V. As for the other structures belonging to the basal ganglia circuitry, whether cortex degeneration follows, accompanies or precedes that of the striatum is still controversial ${ }^{[18]}$.

Up to now, the exact mechanism of HD pathogenesis still remains unclear. Since the genetic cause of HD was uncovered in 1993, several hypotheses have been put forward to elucidate its molecular pathogenesis, including excitotoxicity, oxidative stress, impaired energy metabolism, and abnormal protein-protein interactions - which in turn may cause transcriptional dysregulation and altered gene expression. Central to all hypotheses is the attempt to understand the role of huntingtin (Htt) in normal physiology and in the diseased 
state.

$\mathrm{Htt}$ is encoded by the IT15 gene. Its amino acid sequence does not resemble that of any other known proteins. The 5' end of the IT15 gene contains a polymorphic trinucleotide CAG-repeat which encodes a series of glutamines. Normal people have CAG-repeat lengths of 7-35. The CAG-repeat is expanded and unstable in HD patients. By virtue of having an expanded polyQ, HD becomes a member of neurodegen-erative disorders known as polyQ disorders. The level of expression and the regional distribution of the mutated huntingtin (mHtt) in the brain as well as in the peripheral tissues were found to be rather similar to those of the normal protein ${ }^{[19]}$. Htt is normally distributed predominantly within the cytoplasm; for $\mathrm{mHtt}$, however, nuclear localization is increased ${ }^{[20-22]}$. Htt is ubiquitously expressed, but despite extensively overlapping expression patterns, the neuronal cell death is relatively specific and can differ markedly. The normal function of Htt is poorly understood at present, but it has been proposed to play roles in neurogenesis, apoptosis, and vesicle trafficking. Some of the features of HD may be the result of loss of function of wild-type huntingtin ( $\mathrm{wHtt})^{[23,24]}$.

$\mathrm{HD}$ is a protein misfolding disease. The bio-hallmark of $\mathrm{HD}$ is the formation of intranuclear inclusions (NII) and cytoplasmic aggregates in neurons in vulnerable brain areas. Aggregates of mHtt have been detected both in postmortem tissue from patients affected by the disease and in mouse models of HD. The inclusions and aggregates are usually formed by small N-terminal Htt fragments and are co-localized with other cellular proteins involved in proteolysis, vesicle trafficking and protein degradation. Whether these aggregates are deleterious, protective or incidental remains unclear. Caspases and calpain have been implicated in the cleavage of both $\mathrm{mHtt}$ and $\mathrm{wHtt}^{[25-28]}$. Cleavage of $\mathrm{Htt}$ by caspases results in the production and accumulation of small N-terminal fragments which are prone to form NII and cytoplasmic aggregates and induce apoptosis. Thus N-terminal Htt plays an important role in the pathogenesis of HD. While the traditional view is that the $\mathrm{mHtt}$ is cleared by the ubiquitinproteasome pathway, it is proved that the autophagy-lysosomal route is also involved in the degradation of $\mathrm{mHtt}^{[29-33]}$.

\section{In vivo and in vitro models of HD}

Many animal models mimic HD symptoms or pathology. Characterization of multiple animal models is necessary for understanding the pathogenesis and the effects of potential therapies.

Excitotoxic lesion models Excitotoxicity refers to the deleterious effects produced on neuronal cells by relatively high concentrations of glutamate interacting with its selective membrane receptors. As the striatum receives large glutama-tergic input from corticostriatal afferents, it is a structure at risk of glutamate-mediated excitotoxic injury. The theory of excitotoxicity as a pathogenic mechanism in HD has emerged in the last few decades, beginning with the observation that injections of excitatory amino acids into the striatum of rodents and non-human primates led to neuronal depletion and a neurological phenotype that was similar to HD. The initial reports in 1976 demonstrating that a direct intrastriatal injection of kainate, a non- $N$-methyl- $D$ aspartate (NMDA)glutamate agonist, could mimic the axonsparing striatal lesions observed in HD, was the starting point of a large number of literature on the use of glutamate analogues as neurotoxic compounds in HD research ${ }^{[34]}$. Nevertheless, intrastriatal injections of kainate do not perfectly reproduce the histological hallmarks of $\mathrm{HD}$, since both projection neurons and NADPH-positive interneurons are killed by this excitotoxin, as opposed to the relative sparing of the striatal interneurons in $\mathrm{HD}^{[35,36]}$. In contrast, intrastriatal injections of quinolinate, a NMDA-selective glutamate agonist and an endogenous metabolite of trypophan, induces a preferential degeneration of GABAergic neurons and a relative sparing of NADPH diaphorase- and cholinergic inter-neurons, suggesting that a selective activation of the NMDA receptors is required to mimic HD striatal pathology ${ }^{[37]}$.

Excitotoxin-induced destruction of striatal neurons involves the process of apoptosis ${ }^{[38]}$. Further studies have indicated that the nuclear factor- $\mathrm{KB}(\mathrm{NF}-\kappa \mathrm{B})$ activation contributes to the excitotoxin-induced death of striatal neurons $^{[39]}$. Liang et al evaluated the potential contribution of some apoptosis regulatory proteins such as Bcl-2, p53 and c-Myc to the differential vulnerability of striatal neurons to the NMDA receptor agonist quinolinic acid. They found that selective vulnerability of striatal medium-sized spiny neurons to degeneration in a rodent model of HD appeared to correlate with their low levels of Bcl-2 immunoreactivity and high levels of induced p53 and c-Myc immunoreactivity ${ }^{[40]}$.

Excitotoxic striatal lesions can replicate some of the behavioral aspects of HD including hyperkinesias, impaired motor skills, and deficits in spatial maze learning and executive function in rats. However, the behavioral symptoms fail to include dyskinesias or chorea-like movements ${ }^{[41]}$. The excitotoxic lesion models have led to the use of glutamate antagonists in HD treatment. For example, NMDA receptor antagonists such as riluzole and amantadine are often used clinically. Some data suggest that there are transient 
antichoreatic effects and more sustained effects of riluzole on psychomotor speed and behavior in HD patients ${ }^{[42]}$.

Indirect excitotoxic lesion models (or metabolic toxins models) The injection of various mitochondrial toxins (aminooxyacetate, rotenone, MPP+, malonate, $\mathrm{Mn}^{2+}$, 3-acetylpyridine) into the rat striatum has been shown to produce increased lactate formation, adenosine triphosphate (ATP) depletion and a delayed neuronal degeneration by the mechanism of disrupting mitochondrial energy metabolism and secondary excitotoxicity. The common nature of these lesions was exemplified by the marked degeneration of GABAergic neurons and the relative sparing of cholinergic and NADPH diaphorase-positive interneurons.

The initial identification of 3-nitropropionic acid (3-NP), a metabolite of 3-nitropropanol, as a toxic agent responsible for livestock poisoning, was first made in western USA. Animals intoxicated with leguminous plants presented various motor abnormalities consisting of general weakness and uncoordination of the hind limbs evolving to paralysis ${ }^{[43]}$. The early controlled studies in animals indicated that 3-NP injection could produce hypoxic-like cerebral lesions, preferentially affecting the basal ganglia. In vitro biochemical studies have established that 3-NP is a suicide inhibitor of succinate dehydrogenase, an enzyme located in the mitochondrial inner membrane and responsible for the oxidation of succinate to fumarate ${ }^{[44]}$. Because of the histochemical and pathological similarities between the 3-NP animal model and $\mathrm{HD}$, the $3-\mathrm{NP}$ model has been proposed as an alternative HD model.

Many studies have indicated that acute and large doses of 3-NP administration can not replicate HD pathology. Acute 3-NP toxicity was observed after either 1 or several injections in a short period of time (1-5 d). Depending on the dose administered, the neurological deficits can develop rapidly, ranging from general uncoordination, drowsiness and general weakness to hind limb paralysis without rigidity and finally recumbency and death ${ }^{[45]}$. The histological features observed in the striatum of rats subjected to acute 3NP protocol are quite different from those observed in HD patients. In 3-NP-lesioned brains, the central area of the striatal lesion is totally neuron depletion and there is only a very limited transition zone between the core of the lesion and the normal striatal tissue. Nevertheless, acute 3-NP toxicity has been frequently associated with extra-striatal cerebral lesions involving various brain structures such as the pallidum, the hippocampus, the thalamus and the substantia nigra pars reticulata ${ }^{[46,47]}$.

Chronic intoxication with 3-NP was initially tested in adult rats using a chronic low dose (10-12 $\left.\mathrm{mg} \cdot \mathrm{kg}^{-1} \cdot \mathrm{d}^{-1}, 1 \mathrm{month}\right)$ regimen of administration ${ }^{[47,48]}$. This experimental protocol produced a partial, steady-state metabolic impairment, similar to that found in HD patients. In $30 \%-40 \%$ of the treated animals, chronic 3-NP delivery induced motor abnormalities and selective striatal lesions. Behavioral studies with the chronic 3-NP model indicated that the HD-like striatal lesions were also associated with symptoms and persistent abnormal movements, in many ways analogous to HD motor deficits. In a study performed in animals repeatedly treated with 3-NP (10 $\mathrm{mg} \cdot \mathrm{kg}^{-1}$ every $4 \mathrm{~d}$ for $\left.28 \mathrm{~d}\right)$, a quantitative analysis of spontaneous locomotor behavior showed that this protocol was associated with an early phase of hyperkinesia (first and second week of treatment), followed by a later phase of hypokinesia ${ }^{[49,50]}$.

The animals subjected to the chronic 3-NP intoxication always displayed bilateral and symmetrical dorso-lateral striatal lesions. In their most rostral part, these lesions appeared restricted to the dorso-lateral aspect of the caudate-putamen, whereas a more ventral localization is usually observed caudally. Contrasting with lesions observed in more acute paradigms, the chronic lesion presented a more diffuse cell loss, progressively increasing from the unaffected striatum to the center of the lesion. Within the core of the lesion, an obvious, but partial neuronal loss was noted, accompanied by a moderate astrogliosis, a decrease in cytochrome oxidase activity and a relative sparing of the NADPH diaphorase-positive interneurons and the dopaminergic striatal afferents ${ }^{[46,47,51]}$.

As mentioned previously, the deterioration of cognitive functions in HD is paralleled by the progression of motor effects from a choreic dyskinesia to a more disabling akinetic and parkinsonian-like syndrome. Excitotoxic animal models have not characterized the "progressive" behavioral pathology of HD. In contrast, the progressive locomotor alterations in rats can be obtained when some dosing regimen of 3-NP is administered. Initially, systemically 3-NP-treated animals exhibited significant hyperactivity during the first 2 injections, reaching a plateau after the third injection, and then displaying hypoactivity after the fourth injection ${ }^{[52]}$. The study by Mettler indicates that small lesions are visible at the onset of hypoactivity, but at the end of the long-term course of 3-NP administration, larger lesions were noted; there is no visible striatal degeneration at the period of hyperactivity ${ }^{[53-55]}$.

Despite chronic 3-NP rat models replicating some of the features of HD, this model still has some limitations. Primarily, there is a very different repertoire of movements in the primate compared to the rat. Secondly, the organization of the basal ganglia in primates is quite different from that in rats. 
In primate animals, but not in rats, the striatum is structurally divided into 2 parts: the caudate nucleus and the putamen. This difference between the rodent and primate models is exemplified by the behavioral response to the dopamine agonist apomorphine observed in non-human primates with excitotoxic-induced striatal lesions. In non-human primates with chronic 3-NP treatment, a variety of abnormal movements are highly reminiscent to those seen in HD patients; these types of movements have never been observed in rats in the same experimental conditions. As discussed earlier, rats chronically treated with 3-NP did not show clearly identifiable dyskinetic movements resembling chorea even though hyperlocomotor activity has been reported early in the course of intoxication, as well as the presence of dystonia, bradykinesia and gait abnormalities ${ }^{[46,49]}$. Therefore, it may be that the dyskinetic component of HD symptomatology is part of a motor repertoire that can only be expressed in primates.

The non-human primate HD model also shows the "progressive' characteristics of HD. Hantraye et al treated 2 adolescent baboons for 16 weeks with 3-NP at an initial dose of $10 \mathrm{mg} \cdot \mathrm{kg}^{-1} \cdot \mathrm{d}^{-1}$, which was progressively increased to $28 \mathrm{mg} \cdot \mathrm{kg}^{-1} \mathrm{~d}^{-1}$ (1 $\mathrm{mg} \cdot \mathrm{kg}^{-1}$ increment at weekly intervals). During the first 6 weeks of the protocol, no spontaneous or even apomorphine-induced abnormal movements were observed. The animals were still in the 'non-symptomatic' phase. After 8-10 weeks of treatment, apomorphine administration induced choreiform movements in all 3-NP-treated animals, indicating that at this stage they had entered into the 'presymptomatic' phase, which is characterized by the absence of spontaneous abnormal movements and the presence of frontal deficits and of apomorphine-induced abnormal movements. The severity of motor abnormalities after apomorphine administration increased as the 3-NP intoxication progressed. After 3 months of intoxication, all animals showed spontaneous foot dyskinesia and dystonia, which means they entered into the 'symptomatic phase'. At this stage the animals were killed for pathological examination. Results of postmortem evaluation showed the presence of the bilateral striatal lesions without detectable extra-striatal lesions. Therefore, animal models which mimic the adultonset form of HD were obtained with this protocol ${ }^{[56]}$.

In summary, only chronic systemic administration of 3-NP produces motor dysfunctions and striatal lesions that mimic many histological and neurochemical features of HD. These models also offer the flexibility to investigate HD at different stages. Moreover, the efficacy of experimental treatments can be tested at various times of disease progression. The use of mitochondrial toxin lesion models have led to the clinical administration of mitochondria function protectors, including coenzyme Q10 and creatine for the treatment of HD. However, many studies have shown that these mitochondria function protectors only have limited beneficial effects for HD patients ${ }^{[42]}$. Since the mutant gene that causes HD was identified, numerous genetic animal models have been generated. Because genetic models can mimic the pathology of HD more accurately, chemical lesion models are now considered outdated. However, these models still have some validation. For example, excitotoxin and mitochondrial toxin are often used today in transgenic HD models and other in vitro models to study the sensitivity of genetic models to these toxins ${ }^{[57]}$.

Transgenic mouse models Since the mutant gene that causes HD was identified in 1993, one of the most important advances in HD research has been the generation of various genetic mouse models. Genetic mouse models of HD mainly include transgenic, knock-in, knock-out, and virally-inserted mutated polyQ tract models.

In transgenic mouse models, the mutant gene, or part of it, is inserted randomly into the mouse genome, leading to the expression of a mutant protein in addition to the endogenous, normal Htt. Several transgenic mouse models of HD now exist and fall into 2 broad categories. The first category is mice expressing Htt N-terminal fragments, usually the first 1 or 2 exons of the human $\mathrm{Htt}$ gene that contain the polyQ expansion (in addition to both alleles of murine wHtt, Hdh). The second category is transgenic mice expressing the full-length human HD gene with an expanded polyQ tract (plus the murine Hdh). All these models share some features with human HD. The characteristics in transgenic mice are described by Hickey MA et al. In general, it seems that the shorter the transgene, the longer the CAG repeat, and the higher the expression levels, the more severe the phenotype ${ }^{[58]}$.

Transgenic mice with Htt fragments: The first successful transgenic mouse model of HD was termed the R6 mouse. These mice were generated by overexpressing exon 1 of the human Htt gene with long (141-157) CAG-repeat expansions. To date, 6 lines have been established, in which four lines contain expanded CAG repeats of a size larger than that generally associated with the juvenile $\mathrm{HD}$ patients, namely R6/1, $(\mathrm{CAG})_{115} ; \mathrm{R} 6 / 2,(\mathrm{CAG})_{145} ; \mathrm{R} 6 / 5,(\mathrm{CAG})_{135-156}$; and R6/0, $(\mathrm{CAG})_{142}$. In all cases, except line R6/0 in which the transgene was probably silenced by the site of integration, the transgene protein showed a ubiquitous tissue expression profile. On the basis of home cage behavior, the onset ages are approximately 2 months in line R6/2 and 4-5 months in line R6/1. The movement disorder includes an irregular gait, 
stereotypic grooming movements, rapid shudders and a tendency to clasp the hind limbs and forelimbs together when suspended by the tail. In addition to the movement disorder, the mice exhibit a progressive weight loss. The phenotype progresses rapidly and the mice rarely survive beyond 12 weeks of age ${ }^{[59]}$.

Of the many lines generated, the R6/2 model is the most extensively studied and is readily available commercially. The fast course of the R6/2 makes it a less expensive model to study than others. The R6/2 mice have a well-characterized progressive phenotype with moderate variability such that experimental groups can contain as few as 10 mice to detect $10 \%$ of differences in many outcome measures. It is possible to perform survival studies in approximately 3 months which is lifespan of most R6/2 mice. Motor behavioral deficits could be measured in these mice as early as 5 6 weeks of age. However, overt behavioral anomalies did not appear until 8 weeks, and these were followed by an early death at 10-13 weeks. The mice had a severe phenotype with low weight, diabetes, clasping, tremor and convulsions. At autopsy, brain weight was markedly reduced, but neuronal death was minimal and delayed compared with behavioral symptoms. In contrast, HD is characterized by a massive loss of striatal neurons in humans. Although it is likely that cell death follows a long phase of neuronal dysfunction in both mice and humans, it remains puzzling that this transgenic model did not show overt cell death until the last stages of the disease. An explanation might be the short lifespan of the mouse, which might be caused by general metabolic disease (eg diabetes and severe weight loss) and seizures. Alternatively, because R6/2 mice are relatively resistant to kainic acid in vivo, they might have protective mechanisms that are not present in humans ${ }^{[60-63]}$. Another special mouse model is the N-171-82Q mouse, which has a longer N-terminal fragment of Htt (exon 1 and 2) with 82 polyQ. These mice have a less well-defined neurobehavioral phenotype than that of R6/2 mice. Their neuropathological features are more similar to human HD in that Htt aggregates are more prominent in the cortex than in the striatum, and neurodegeneration is more prominent and seems more selective for the striatum. However, the phenotype is more variable than that of the R6/2 mice and therefore, a much larger number of mice (more than 20 in each treatment group) are necessary to provide better accuracy in detecting statistical significance of changes ${ }^{[64]}$.

Although these mice show rather little overt cell death, it was in this strain that the NII were first demonstrated, suggesting that the phenotype is an expression of abnormal function of cells expressing the mutant protein rather than a result of cell death. The discovery of NII in the brains of these transgenic mice came at a time when similar features were reported in models of other CAG-repeat diseases, suggesting a common pathological mechanism of these diseases $^{[65-68]}$. This triggered a flurry of studies aimed at identifying the components of inclusions, the mechanism of $\mathrm{Htt}$ aggre-gation, the role of NII in neurotoxicity and ways to prevent Htt aggregation.

Although the transgenic mice with fragments display many of the behavioral and neuropathological features observed in HD patients, it is not a perfect genetic and neuropathological match to that observed in humans. For example, the R6/2 mice have more extensive Htt aggregate formation than what occurs in $\mathrm{HD}$, they are resistant to excitotoxicity and neuronal loss is less selective and dramatic. In addition, the pathogenic mechanism of the truncated Htt in these mouse models is questionable. The major problem is all these fragments chosen have no physiological ground because these fragments may not be produced in the human HD brain. Since Htt is a big protein with many potential functional domains, its conformation and function may show variable changes and thus, create artificial properties when Htt is cut into different sizes of fragments. These would make many findings in transgenic HD mice expressing N-terminal fragments hard to relate to HD pathogenic mechanisms ${ }^{[64]}$.

Transgenic mice with full-length Htt: Several mouse models have been generated using a full-length human IT15 gene as the transgene. Unfortunately, some of these models are not successful. For instance, Goldberg et al generated transgenic mice that carried full-length human Htt with 44 CAG repeats. No protein expression was detected and there was no indication of neuronal loss, neurodegeneration or behavioral abnormalities ${ }^{[69]}$, but with the CAG repeats increased, the symptoms and pathology of transgenic mice models become more significant. For instance, mice that express a full-length IT15 cDNA clone with either 48 or 89 repeats driven by the cytomcgalovirus promoter (CMV) showed a progressive motor phenotype, and more importantly, neuronal loss in the striatum. Surprisingly, NII were extremely rare in these mice. A similar feature is shared by a yeast artificial chromosome (YAC) mouse expressing a full length IT15 gene with 72 repeats. Although these mice did not have NII, much smaller aggregates of Htt were observed in the nucleus. Disease progression was slow in the YAC mice, which correlates with a smaller repeat length and a much lower level of transgene expression (30\%-50\%). An attractive feature of the YAC mice is that cell loss is limited to the striatum, thus recapitulating to some extent the regional selectivity of $\mathrm{HD}^{[70,71]}$. 
Jeremy et al also studied the selective degeneration of neurons in YAC128 mice. They found that these mice exhibit selective atrophy and neuronal loss in a pattern similar to human HD. Although the striatum does not show increased $\mathrm{mHtt}$ expression, nuclear localization of $\mathrm{mHtt}$ occurs earlier and to a greater extent in the striatum, suggesting the possibility that selective nuclear localization of $\mathrm{mHtt}$ may contribute to the selective neurodegeneration in HD. Furthermore, the appearance of $\mathrm{mHtt}$ in the nucleus coincides with the onset of behavioral abnormalities, suggesting that this may contribute to neuronal dysfunction. A comparison to R6/1 mice reveals non-selective nuclear detection of $\mathrm{mHtt}$ in these mouse models and suggests that the expression of full-length mHtt may be important in modeling the selective neuropathology in $\mathrm{HD}^{[72]}$. Tanaka et al have generated an inducible mouse model of HD expressing full-length Htt with 148Q using a doxycycline-regulated promoter. In inducible transgenic mice, Htt was expressed widely in the brain under the control of the Tet-transactivator driven by the prion promoter. They found that there were prominent NII in the cortex and striatum, as well as cytoplasmic aggregates. Their further studies showed that the distribution of the inclusions and other aggregates were more widespread than that typically seen in HD patients, with inclusions prominent not only in the cortex and striatum, but also in the hippocampus, brain stem and cerebellum. There may be 2 reasons for this: First, their constructs have a very long polyQ repeat (with 148Q); HD patients with longer polyQ repeats also tend to have more widespread pathology. Second, expression is driven not by the Htt promoter, but by the prion protein promoter ${ }^{[73]}$.

The prominent difference between transgenic mice with full-length HD and human HD is the relative lack of marked neuronal cell death in mice striatum. There is increased glial fibrillary acidic protein (GFAP) labeling, characteristic of astrogliosis, and ventricular enlargement, consistent with neurodegeneration, but there does not appear to be massive neuronal loss in the striatum. In this respect, transgenic mice models with full-length $\mathrm{mHtt}$ are similar to other genetic mouse models of HD. While there has been some degree of degeneration and astrogliosis in several of these models, none of them reproduce the massive selective neuronal cell death of up to $95 \%$ of medium spiny neurons that can be seen in advanced HD patients ${ }^{[73]}$.

Compared to transgenic mice with truncated gene, the neuropathology of transgenic mice with full-length Htt has greater fidelity with human disease. However, the N-terminal fragment mice generally have a more obvious behavioral and pathological phenotype than mice expressing full-length Htt. The variability and the slow phenotype development of models expressing full-length Htt may hinder its use for the research of potential therapeutic compounds. In contrast, the efficiency and clear experimental endpoints are the major advantages of $\mathrm{N}$-terminal fragment mice and are also the reasons for its widespread use in HD research.

Knock-in mouse models In theory, knock-in models are the most faithful genetic models of the human HD condition, since knock-in mice carry the mutation in its appropriate murine genomic and protein context and under the endogenous Hdh promoter. However, these models were disappointing initially because the mice showed either no behavioral phenotypes or anomalies that apparently did not involve movement disorders. This initial disappointment was later dispelled after closer analysis and generation of additional models ${ }^{[74,75]}$. Homozygous knock-in mice have now been shown to develop very early behavioral anomalies prior to any detectable neuropathology. These mice carried 94 CAG repeats and behavioral data suggested that cellular dysfunction (prior to $\mathrm{mHtt}$ aggregation) was responsible for the initial symptoms of HD. The mice showed abnormal activity levels that were biphasic and mirrored the progression of motor symptoms in HD. Therefore, knock-in mouse models represent a valid model of $\mathrm{HD}$, with the added advantage of a slower progression of phenotype and pathology, thus allowing more detailed analysis ${ }^{[76,77]}$.

So far, the knock-in mice do not have sufficient expression of disease to use progressive morbidity and survival as an endpoint; however, they have a variety of measurable neuropathological and behavioral phenotypes that could be validated as potential endpoints in therapeutic studies. A common feature of different knock-in mice models is the presence of nuclear staining and microaggregates of $\mathrm{Htt}$ in the brains of mice at 2-6 months of age, which is relatively early in the course of the disease. By contrast, NII are only observed when the mice are older (10-18 months of age), and cell death has not been reported. Overt neuronal loss and gliosis, even in older animals, is absent. However, molecular alterations (decrease in mRNA encoding enkephalin in the striatum) and cellular alterations (increased sensitivity to NMDA) similar to those observed in the R6/2 mice were present in the 94-CAG-repeat knock-in mice. The presence of these clear anomalies further suggests that neuronal dysfunction precedes cell death in HD and might be primarily responsible for early functional deficits. This correlates with the finding that subtle motor deficits precede by many years the appearance of overt symptoms and striatal atrophy in HD patients. Further crucial information obtained from knockin mice is evidence of an age-related instability of expanded $\mathrm{CAG}$ repeats in neurons, despite the fact that mature neu- 
rons do not divide. Importantly, this instability is regionspecific, with larger increases in CAG numbers found in the striatum and cortex. Because there is a clear relationship between the number of CAG repeats and the toxicity of $\mathrm{mHtt}$, this could be a reason for the regional selectivity of neuronal loss in adult-onset $\mathrm{HD}^{[78,79]}$.

In summary, genetic mouse models provide insight into the pathogenesis of HD and are invaluable tools for the evaluation of potential therapeutic approaches. The widespread use of genetic mice has led to some important discoveries in HD molecular pathogenesis, including misfolding and aggregation, abnormal protein interactions and dysregulation of transcription conferred on mHtt. Meanwhile, genetic mice have also led to the emergence of many potential chemicals which may correct these acquired properties. These compounds may inhibit $\mathrm{mHtt}$ aggregation, transglutaminase, protease or histon deacetylase in animal experiments ${ }^{[42]}$.

The knock-out mice model Soon after the discovery of the gene mutation that causes HD, it was found that homozygous gene knock-out in mice was embryonic lethal, which contrasts with the late onset of the human disease. Thus, these early knock-out mice are not good HD models, but they indicate that Htt has an essential role in embryonic development. Furthermore, mHtt can rescue the knock-out phenotype, which indicates that the effect of the mutation is not primarily due to loss of function ${ }^{[80-83]}$. Htt contains a polymorphic stretch of polyQ near its N-terminus. HD results when the polyQ stretch is expanded beyond $37 \mathrm{Q}$. However, the role of the normal polyQ stretch in the function of Htt is unknown. Clabough et al deleted the CAG triplet repeat encoding $7 \mathrm{Q}$ in the mouse $\mathrm{HD}$ gene $\left(\mathrm{Hdh}^{\Delta \mathrm{Q}}\right)$ to determine the contribution of the polyQ stretch to normal Htt function. They found these Hdh(DQ/DQ) mice are born with normal Mendelian frequency and exhibit no gross phenotypic differences in comparison to control littermates, suggesting that the polyQ stretch is not essential for Htt's functions during embryonic development. However, adult mice commit more errors initially in the Barnes circular maze learning and memory test and perform slightly better than wildtype controls in the accelerating rotarod test for motor coordination. The polyQ deletion results is only a subtle phenotype in vivo, thus, it is likely that the polyQ stretch is not required for an essential function of $\mathrm{Htt}$, but instead, may modulate a normal function of $\mathrm{Htt}^{[84]}$

Mouse models with virally-inserted mutated polyQ tracts Viral-vector aided insertion in genes, whether in full or partial, has the advantage of precise localization of injection and gene expression. There are 2 types of viral vectors currently used. These include adeno-associated and lentiviral, both of which integrate into the host genome. These kinds of models are more labor-intensive than transgenic or knock-in mice. However, this technology is applicable to non-rodent species in a way that is not currently possible with transgene or knock-in technology. These models can be used to study the effects of discrete amounts of the $\mathrm{mHtt}$ protein and can also be used to study load, temporal and spatial effects of the mutation in more controlled circumstances than in transgenic or knock-in animals. In addition, the effect of different viral vector inserts can be compared, potentially in the same animal. This may be important since genetically identical animals with the same mutant polyQ transgene develop very different amounts of aggregates of the $\mathrm{mHtt}$ pro$\operatorname{tein}^{[85,86]}$.

Senut et al examined the effect of a polyQ (97Q) repeat expression in the context of an adeno-associated viral vector (AAVV). High levels of expression of the polyQ tract led to development of nuclear and cytoplasmic aggregates as early as $5 \mathrm{~d}$ post infection. This indicates that expression of the polyQ alone is highly associated with the development of inclusion bodies. Aggregates were also observed at a distance from the injection site, indicating that anterograde and retrograde transport of the vector had taken place. In theory, lentiviral vectors are capable of carrying larger transgenes than AAVVs. de Almeida et al also found that expression levels of the transgene were proportional to the severity of neuropathology. In addition, increased expression led to the production of NII, whereas neuritic and nuclear aggregates were observed when expression was driven by a weaker promoter. Longer CAG-repeat lengths correlated with increased aggregate formation. Loss of staining for aggregated $\mathrm{mHtt}$ near the injection site was attributed to cell death and proportional to high expression levels. Importantly, choline acetyltransferase (ChAT) and NADPH-d interneurones were relatively preserved as the same feature of human $\mathrm{HD}^{[85,87]}$.

Fly (Drosophila) models The fly is one of the best invertebrates for modeling higher organisms. Comparative genome analysis reveals that at least $50 \%$ of fly genes are similar to those of humans ${ }^{[88]}$. Among those human genes known to be associated with disease, $75 \%$ have a Drosophila ortholog ${ }^{[89]}$. Analysis of the genomic and cDNA sequences indicates that the Drosophila HD gene has 29 exons, compared with the 67 exons present in vertebrate HD genes, and that Drosophila Htt lacks the polyQ and polyproline stretches presented in its mammalian counterparts ${ }^{[0]}$. The fly is also an excellent choice for modeling neurodegenerative diseases because it contains a fully functional nervous system with an architecture that separates 
specialized functions such as vision, olfaction, learning and memory. Further, the compound eye of a fruit fly is made up of hundreds of repeating constellations of photoreceptor neurons such that any perturbation in the pattern is quite evident. Most importantly, in Drosophila, foreign genes can be engineered to be expressed in tissue-specific and temporally regulated patterns and an impressive array of genetic tools are available ${ }^{[91]}$.

Foreign genes are expressed using a bipartite gene expression system in which genes inserted behind the yeast upstream activator sequence (UAS) are activated by the yeast Gal4 protein. Genes fused to UAS and injected into embryos with a helper element integrate into the chromosome producing transgenic lines carrying the UAS transgene. Many measures of neuronal dysfunction are possible, with some of the most common ones being climbing ability or integrity of photoreceptor cells of the eye $\mathrm{e}^{[92,93]}$. In all models studied, it has been found that pathology exhibits a polyQ length dependency similar to that of humans. Drosophila embryogenesis spans approximately $1 \mathrm{~d}$, and neurogenesis begins at about $5 \mathrm{~h}$ and concludes by about $15 \mathrm{~h}$. To our knowledge, no evidence of neurodegeneration has previously been described early in the larval stages, but clear evidence of degeneration occurs in mature larvae, in pupae and in aging adults. Thus, by every measure, flies expressing mutant human genes present with pathology that mimics the human disease in every important way ${ }^{[94,95]}$. How to make Drosophila models more amenable to high-throughput and automated screening for therapeutics is an important issue. In this regard, practical hurdles to be overcome are the automated manipulation and scoring of flies and the fact that flies are not accessible to externally administered drugs.

Caenorhabditis elegans models The nematode Caenorhabditis elegans (C elegans) is an established model for developmental biology. Parker et al expressed the first 57 amino acids of human Htt with normal and expanded polyQ fused to a fluorescent protein marker in C elegans touch receptor neurons by using the mec-3 promoter (Pmec-3). Pmec- 3 is active in 6 touch receptor neurons needed for gentle touch. Because $C$ elegans does not contain a $\mathrm{Htt}$ homolog nor long polyQ tracts, transgenic phenotypes in worms can be attributed to polyQ transgenes ${ }^{[96-98]}$. In $C$ elegans, expanded polyQ produces mild nose touch abnormalities and low penetration of dye-filling defects, and causes cell death when expressed in sensitized ASH sensory neurons under the control of the osm-10 promoter. Perinuclear protein accumulation was observed in tail mechanosensory neurons, the phospholemman (PLM) cells, but did not correlate with polyQ length or the mechanosensory defective
(Mec) phenotype. Animals expressing 128 Gln residues (Glns) were strongly $\mathrm{Mec}$ at the tail and more likely to have aggregates in PLM neuronal processes. Additionally, neurons appeared to show selective susceptibility to polyQ-mediated degeneration. The difference in penetrance between anterior and posterior touch responsiveness may reflect neuronal susceptibility to polyQ toxicity. These observations are consistent with another observation that mechanosensory neurons of the Drosophila eye are resistant to polyQinduced toxicity, whereas photoreceptor neurons are highly sensitive. Most notably, PLM neuronal processes in these animals also display morphological abnormalities, and neuronal dysfunction occurs in the absence of cell death. Importantly, studies of these animals also indicate that polyQ-mediated neuronal dysfunction is independent of cell body aggregates and partially correlates with aggregation in neuronal processes and abnormal morphology of axons ${ }^{[99,100]}$.

Yeast HD models Although several transgenic animal models exist for studying the functions of $\mathrm{Htt}$, none are as readily amenable to genetic analysis as yeast. Yeast models of HD have been created primarily by transgene approaches using glutamine-encoding trinucleotide expansions. To provide a genetically tractable model system for the study of $\mathrm{Htt}$, Krobitsch et al engineered yeast cells to express an Nterminal fragment of $\mathrm{Htt}$ with different polyQ repeat lengths. Homopolymeric tracts of $\mathrm{CAG}$, the naturally occurring glutamine codon in $\mathrm{Htt}$, are inherently unstable, and particularly so in yeast. To reduce this problem, the CAG and Cytosine Adenine Adenine (CAA)-mixed codon polyQ repeats were performed in their experiments according to the fact that glutamine is encoded by both CAG and CAA and that mixed-codon repeats are considerably more stable ${ }^{[101-103]}$. The results indicate that the extent of aggregation varies with the length of the polyQ repeat. At the 2 extremes, most HtQ103 protein coalesced into a single large cytoplasmic aggregate, whereas HtQ25 exhibited no sign of aggregation. Further-more, the polyQ fragments of Htt exhibited minimal toxicity in yeast, whether they were present in the aggregated or soluble state ${ }^{[104]}$.

In humans, Htt proteins with the longer repeat expansions not only produce disease earlier, but also expand the cell-type distribution of toxicity. Lack of toxicity for the aggregated and soluble Htt fragments in yeast is advantageous for 3 reasons. First, it provides an opportunity to study natural cellular factors that control the fate of misfolded polyQ proteins and to search for potential therapeutic agents that affect misfolding, aggregation and degradation, without the complication of deciphering the contributions of toxicity to the outcome of the assay. Second, polyQ-expanded pro- 
teins may perturb the distribution of other cellular proteins by providing novel interaction surfaces ${ }^{[105,106]}$. The nature of these interactions is most readily and rapidly tested in an environment where the aggregation state of the polyQ protein can readily be manipulated. Finally, the greatest conundrum of the polyQ diseases may be that most of the proteins are ubiquitously expressed, yet each manifests its toxicity in a unique and distinct set of neurons. Yeast screens with different polyQ proteins may provide an opportunity to identify the cell type-specific factors that contribute to the unique spectrum of toxicities and subsequently, to search for factors that ameliorate their effects ${ }^{[106]}$.

Cell culture models of HD Gene expression studies conducted with HD animal models have revealed profound modifications in gene transcription. However, the complexity of in vivo tissue hampers definition of very early transcriptional modifications and does not allow discrimination between cell-autonomous changes and those resulting from intercellular activity processes. An inducible, clonally derived, cell line expressing mHtt can offer a stable and controlled genetic and transcriptional background in which to perform gene expression studies. In such a system, biological and experimental variability can be greatly reduced. Several cell models of $\mathrm{HD}$ are available. One of them is a mouse neuron which has been fused with mouse teratoma cells, and the resulting hybrids have been stably transfected with various polyQ-containing peptides. Another available model is based on stably transfected, temperature-sensitive, immortalized mouse striatal neurons ${ }^{[107,108]}$.

Stable, inducible PC12 models of HD expressing wildtype and mutant Htt, either in the context of an exon 1 fragment or the full-length protein, have been employed. These models exhibit normal morphology and growth patterns which are indistinguishable from the parental PC12 Tet-On line, together with high transgene inducibility and low background. These cell lines expressed similar levels of endogenous and exogenous mHtt, analogous to the heterozygous condition. Compared with the exon 1 model, these fulllength cell lines exhibited very low levels of cell death in cycling cells. The mutant polyQ lines also exhibited timedependent aggregate formation, in both the nucleus and cytoplasm. ST14A cells, derived from rat embryonic striatum, were also used to generate inducible cell lines expressing the N-terminal fragment of Htt. The advantage of these models is that we can study events without the complications of cell death, because cell death in the mutant, mitotic lines is very low and is no higher than that of the wild type lines ${ }^{[109,110]}$.

Cell models to elucidate the molecular pathogenesis of HD have been used. Many hypotheses have been produced based on cell models studies in vitro. Some investigators have explored the role of autophagy in Htt processing in 3 cell lines: clonal striatal cells, PC12 cells and rodent embryonic cells lacking cathepsin D. Results suggest that autophagy plays a critical role in the degradation of N-terminal Htt. Blocking autophagy raises levels of exogenously expressed $\mathrm{Htt}$, reduces cell viability and increases the number of cells bearing $\mathrm{mHtt}$ aggregates. Stimulating autophagy promotes Htt degradation, including the breakdown of caspase cleaved $\mathrm{N}$-terminal Htt fragments. They also found that Htt expression increases levels of the lysosomal enzyme cathepsin D by an autophagy-dependent pathway. These results indicate that altered processing of $\mathrm{mHtt}$ by autophagy and cathepsin D may contribute to HD pathogenesis ${ }^{[111]}$. The mammalian target of rapamycin is a kinase which can inhibit autophagy in cells from yeast to humans. Rapamycin is a specific inhibitor of mammalian target of rapamycin (mTOR) which can stimulate autophagy. Rapamycin is lipophilic and demonstates good blood-brain barrier penetration. These results indicate that rapamycin is a good chemical candidate for use in treating HD. Ravikumar et al found that the ability of rapamycin to inhibit mTOR activity may be impaired after prolonged Htt expression and thus increased aggregate formation. Therefore, early treatment with rapamycin may attenuate $\mathrm{HD}^{[112]}$.

\section{Classification and evaluation of HD models}

As described earlier, there are many animal models which mimic some aspects of HD symptoms or pathology. Characterization of multiple animal models is necessary to understand the mechanism of pathogenesis and the effects of potential therapies. According to the different methods of classification, HD models can be divided into several respective categories. According to the mechanism of replication, HD models can be divided into chemically-induced animal models and genetic animal models. The chemically-induced HD models are the earliest models which were widely used before the identification of the HD gene, including excitotoxic lesion models (glutamate, kainic acid, quinolinic acid-induced) and mitochondrial dysfunction models (3-NP, malonate-induced). Genetic animal models, which are the most recent of HD models, can be subdivided into transgenic (expressing the full-length or fragment of HD gene), knock-in, knock-out and virally-inserted mutated polyQ tract models. It is well known that HD is a hereditary neurodegenerative disorder known as one of the CAG trinucleotide repeat disorders. Therefore, genetic models mimic the molecular pathogenesis of HD more closely than that of 
chemical lesion models.

According to the species of model animals, HD models can be divided into cell-free and cell culture models, lower organisms (such as yeast, Drosophila, C elegans, zebrafish), rodent models (mouse, rat), and non-human primate models (monkey and baboon). The outcome measure of cell culture or cell-free models is cytotoxicity or some structural or biochemical measure related to pathogenesis which is especially suitable for high-throughput screening. Lower organisms can provide a more salient context for the genetic mutation and opportunity for genetic analyses. The disease expression and response to potential therapies of the mammalian models can be quite close to that occurring in humans. Rodent and non-human primates are particularly useful to elucidate aspects of the disease that are related to neuronal circuitry, a feature not reproduced in in vitro models or lower animals.

After classification, the next crucial question is how to evaluate these models. Are there some advantages and limitations of each model? Which model is the best model to closely mimic the symptoms and pathology of HD? In order to answer these questions, we should first establish a standard. The ideal mouse model would have the following characteristics: (1) a robust phenotype, well-defined neurobehavioral abnormalities which are easy to be quantified; (2) neuropathological findings which accurately mirror human patients; (3) rapid disease onset and progression; and (4) limited variability to enhance study accuracy ${ }^{[113]}$.

To date, there is no model which satisfies all the standards described above. Among all the HD models, including the 3-NP lesion model, R6/2 and R6/1 mice, N171 mice and YAC72 mice models studied in the most detail, it was established that each model has its own inevitable advantages and limitations. For example, chronic systemic administration of 3-NP produces motor dysfunctions and striatal lesions that share many of the characteristic histological and neurochemical features of HD, therefore, this kind of model has attracted much attention over the last decades. However, although metabolic toxin models may provide a higher level of neuropathological validity, the interanimal variability and the incidence of gross nonspecific striatal damage are higher than that of excitotoxin lesion models and it requires very slow chronic titration of delivery to achieve an acceptable level of specificity.

Another example is the genetic mouse model. Lots of genetic models have been created and all of these models share some features with human HD. Both strains of R6 mice exhibit little cell death and neuritic pathology, but widespread NII. N171 mice show striatal cell death and widespread NII.
YAC72 mice, which contain the entire human gene and the human promoter, show variable amounts of hyperactivity at about 1 year and then become less active, displaying striatal pathology and evidence of apoptotic cell death ${ }^{[14]}$. In general, the more similar to the human HD, the more closely the model reproduces the exact neuropathological and molecular conditions for HD. Unfortunately, the more genetically accurate the model (for example, YAC 128, YAC72 mice), the more variable and subtle the phenotype. Thus, it has so far been much more feasible to use the fragment models (R6/2, $\mathrm{R} 6 / 1$ mice) for therapeutics research because the outcomes are more prevalent and definable ${ }^{[113]}$. An emerging strategy is to use the fragment models for most experiments and fulllength transgenic or knock-in mice for confirmatory studies once the potential of a compound has been established. Until there is more feedback from human therapeutic experiments, it will not be known whether the fragment mouse models stand on their own as predictors of responses to therapies or whether the full-length models are even necessary.

\section{Implications of HD models in developing candidate therapies}

Animal models provide an opportunity to test potential treatments and explore their promise for translation to humans. In the last several years, animal models of HD have been extensively used to test potential therapies. In order to get effective and safe medicines from thousands to millions of small molecules, high-throughput screening should first be carried out. When the lead compounds arise, proof of efficacy in mammalian models is considered a prerequisite before considering possible testing in humans.

High-throughput screening techniques are essential for the identification of potential treatments. Cell-free, cultured cell and other lower organism models are often used in the process of high-throughput screening, in which to explore the effect of small molecules on some specific molecular targets in the disease process. Potential targets for highthroughput chemical screenings include molecular chaperones, caspases, the ubiquitin/proteasome proteases, transcription factors, and the offending polyglutamine-containing proteins themselves. Much attention has been focused on screening for drugs that prevent aggregation of Htt with the expanded polyQ tract ${ }^{[42]}$. Since aggregates are such ubiquitous hallmarks of neurodegenerative diseases, polyQ aggregates are a tempting target for high-throughput screening of pharmacological agents that might block or disrupt aggregate formation. Many cell-free and cell-based screens have been developed ${ }^{[15-118]}$. However, the potential effi- 
cacy of aggregate preventing compounds in relieving pathology must be addressed in vivo.

Live animal screens exhibit inherently lower throughput than cell or cell-free-based screens. However, they can filter out a large number of false leads in the early phases of screening. Efforts to automate and improve the throughput of live animal screens are underway. High-throughput screening is also being planned using transgenic HD mice. Hickey et al have identified early behavioral deficits in tests of motor function that are amenable to cost effective automated analysis in R6/2 mice. Running wheel activity and climbing behavior were reduced in R6/2 mice from as early as 4.5 weeks of age, at a time when rotarod performance and grip strength were still normal. Power calculations showed that the running wheel test could detect improvement with manageable group sizes. This test can be automated and requires little manual input. Therefore, the running wheel test is appropriate for efficient, high-throughput drug screening at an early age ${ }^{[119]}$.

Identification of lead compounds from high-throughput screening then proceeds to animal testing where a large number drop out, either because they do not ameliorate the disease process in vivo or because of some unwanted side effects. Therefore, this process of drug development is slow and expensive. It could proceed more rapidly and at lower cost by using non-vertebrate organisms that can be genetically engineered and have short generation times that allow rapid identification of the most promising strategies. Drosophila models have proven effective in rapidly allowing the efficacy of various pharmacological and synthetic peptide agents on neuropathology to be tested ${ }^{[118,120]}$.

Apostol et al have developed inducible PC12 cell-culture models to screen for loss of visible aggregates. To test the validity of this approach, compounds that inhibit aggregation in the PC12 cell-based screen were tested in a Drosophila model. The disruption of aggregation in PC12 cells strongly correlates with the suppression of neuronal degeneration in Drosophila. Thus, the engineered PC12 cells coupled with the Drosophila model provide a rapid and effective method to screen and validate compounds ${ }^{[121]}$. The concordance of compounds that are effective in both fly and mouse models of HD underscores the utility of using fly models of human disease to screen for target pathways. It also argues that wider use of invertebrate systems to screen directly for compounds that lead to functional neurological improvement may be effective ${ }^{[122-124]}$.

\section{Summary and conclusion}

As described earlier, there are many animal models closely mimicking HD symptoms or pathology. They include chemical-induced HD animal models, genetic animal HD models in which cell-free and cell culture, lower organisms (such as yeast, Drosophila, C. elegans, zebrafish), rodent (mouse, rat) and non-human primates are involved. These animal models provide some accessible systems in which to study molecular pathogenesis and to test potential treatments. Among these models, 3-NP induced and R6/2 transgenic mouse models are most commonly used. Because HD is an inherited disorder caused by gene mutation, genetic models more faithfully replicate the human condition than chemical lesion models. Among all the genetic models, knock-in mice have the advantage of carrying the mutation in the appropriate protein context, the full-length Huntington protein and under the endogenous promoter which makes knock-in mice the most valuable models at present.

Currently, screening for drugs and therapeutics takes place in many laboratories. However, the development of more effective therapies may not come until better animal models are available for evaluation of a drug's efficacy. The usefulness of genetic models is invaluable and the seminal multidisciplinary work promises a very exciting future for understanding the pathological mechanisms of HD and for devising new avenues for treatment. Despite this promising beginning, none of the models replicate the massive cell loss of striatal neurons occurring in human patients. Much remains to be done to create mechanistically significant, full models of this disease. A combination of new genetic approaches and closer mimicking of the environment in which the disease develops in humans is required.

\section{References}

1 The Huntington's Disease Collaborative Research Group. A novel gene containing a trinucleotide repeat that is expanded and unstable on Huntington's disease chromosomes. Cell 1993; 72: 971-83.

2 Brinkman RR, Mezei MM, Theilmann J, Almqvist E, Hayden MR. The likelihood of being affected with Huntington disease by a particular age for a specific CAG size. Am J Hum Genet 1997; 60: $1202-10$.

3 Beal MF. Aging, energy, and oxidation in neurodegenerative diseases. Ann Neurol 1995; 38: 357-66.

4 Cattaneo E. Dysfunction of wild type huntingtin in Huntington disease. J News Physiol Sci 2003; 18: 34-7.

5 Brouillet E, Condea F, Beal MF, Hantraye P. Replicating Huntington's disease phenotype in experimental animals. Prog Neurobiol 1999; 59: 427-68.

6 Foroud T, Gray J, Ivashina J, Conneally PM. Differences in duration of Huntington's disease based on age at onset. J Neurol Neurosurg Psychiatry 1999; 66: 52-6.

7 Leegwater J, JangHo K, Cha J. The paradigm of Huntington's 
disease: therapeutic opportunities in neurodegeneration. Am Soc Exp NeuroTher 2004; 1: 128-38.

8 Vonsattel JP, Myers RH, Stevens TJ, Ferrante RJ, Bird ED, Richardson EP. Neuropathological classification of Huntington's disease. J Neuropathol Exp Neurol 1985; 44: 559-77.

9 Dawbarn D, De Quidt ME, Emson PC. Survival of basal ganglia neuropeptide Y-somatostatin neurones in Huntington's disease. Brain Res 1985; 340: 251-60.

10 Ferrante RJ, Kowall NW, Beal MF, Richardson EP Jr, Bird ED, Martin JB. Selective sparing of a class of striatal neurons in Huntington's disease. Science 1985; 230: 561-4.

11 Ferrante RJ, Kowall NW, Beal MF, Martin JB, Bird ED, Richardson EP. Morphologic and histochemical characteristics of a spared subset of striatal neurons in Huntington's disease. J Neuropathol Exp Neurol 1987; 46: 12-27.

12 Kowall NW, Ferrante RJ, Martin JB. Patterns of cell loss in Huntington's disease. Trends Neurosci 1987; 10: 24-9.

13 Cicchetti F, Parent A. Striatal interneurons in Huntington's disease: selective increase in the density of calretinin-immunoreactive medium-sized neurons. Mov Disord 1996; 11: 619-26.

14 Hedreen JC, Folstein SE. Early loss of neostriatal neurons in Huntington's disease. J Neuropathol Exp Neurol 1995; 54: 10520 .

15 Martin JB. Molecular basis of the neurodegenerative disorders. N Engl J Med 1999; 340: 1970-80.

16 Ho LW, Carmichael J, Swartz J, Wyttenbach A, Rankin J, Rubinsztein DC. The molecular biology of Huntington's disease. Pyschol Med 2001; 31:3-14.

17 Tobin AJ, Signer ER. Huntington's disease: the challenge for cell biologists. Trends Cell Biol 2000; 10: 531-6.

18 Cudkowicz M, Kowall NW. Degeneration of pyramidal projection neurons in Huntington's disease cortex. Ann Neurol 1990; 27: 200-4.

19 Aronin N, Chase K, Young C, Sapp E, Schwarz C, Matta N, et al. CAG expansion affects the expression of mutant huntingtin in the Huntington's disease brain. Neuron 1995; 15: 1193-201.

20 Martindale D, Hackam A, Wieczorek A, Ellerby L, Wellington C, McCutcheon $\mathrm{K}$, et al. Length of huntingtin and its polyglutamine tract influences localization and frequency of intracellular aggregates. Nat Genet 1998; 18: 150-4.

21 Kegel KB, Meloni AR, Yi Y, Kim KY, Doyle E, Cuiffo BG, et al. Huntingtin is present in the nucleus, interacts with the transcriptional corepressor $\mathrm{C}$-terminal binding protein, and represses transcription. J Biol Chem 2002; 277: 7466-76.

22 Sugars KL, Rubinsztein DC. Transcriptional abnormalities in Huntington disease. Trends Genet 2003; 19: 233-8.

23 DiFiglia M, Sapp E, Chase K, Schwarz C, Meloni A, Young C, et al. Huntingtin is a cytoplasmic protein associated with vesicles in human and rat brain neurons. Neuron 1995; 14: 1075-81.

24 White JK, Auerbach W, Duyao MP, Vonsattel JP, Gusella JF, Joyner AL, et al. Huntingtin is required for neurogenesis and is not impaired by the Huntington's disease CAG expansion. Nat Genet 1997; 17: 404-10.

25 Goldberg YP, Nicholson DW, Rasper DM, Kalchman MA, Koide $\mathrm{HB}$, Graham RK, et al. Cleavage of huntingtin by apopain, aproapoptotic cysteine protease, is modulated by the polyglutamine tract. Nat Genet 1996; 13: 442-9.

26 Wellington CL, Ellerby LM, Hackam AS, Margolis RL, Trifiro
MA, Singaraja R, et al. Caspase cleavage of gene products associated with triplet expansion disorders generates truncated fragments containing the polyglutamine tract. J Biol Chem 1998; 273: 9158-67.

27 Goffredo D, Rigamonti D, Tartari M, De Micheli A, Verderio C, Matteoli M, et al. Calcium-dependent cleavage of endogenous wild-type huntingtin in primary cortical neurons. J Biol Chem 2002; 277: 39 594-8.

28 Gafni J, Ellerby LM. Calpain activation in Huntington's disease. J Neurosci 2002; 22: 4842-9.

29 Davies SW, Turmaine M, Cozens BA, DiFiglia M, Sharp AH, Ross CA, et al. Formation of neuronal intranuclear inclusions underlies the neurological dysfunction in mice transgenic for the HD mutation. Cell 1997; 90: 537-48.

30 DiFiglia M, Sapp E, Chase O, Davies SW, Bates GP, Vonsattel JP, et al. Aggregation of Huntingtin in neuronal intranuclear inclusions and dystrophic neurites in brain. Science 1997; 277: 1990-3.

31 Scherzinger E, Lurz R, Turmaine M, Maggiarini L, Hollenbach B, Hasenbank R, et al. Huntingtin-encoded polyglutamine expansions form amyloid-like protein aggregates in vitro and in vivo. Cell 1997; 90: 549-58.

32 Qin $\mathrm{ZH}, \mathrm{Gu} \mathrm{ZL}$. Huntingtin processing in pathogenesis of Huntington disease. Acta Pharmacol Sin 2004; 25: 1243-9.

33 Ravikumar B, Duden R, Rubinsztein DC. Aggregate-prone proteins with polyglutamine and polyalanine expansions are degraded by autophagy. Hum Mol Genet 2002; 11: 1107-17.

34 McGeer EG, McGeer PL. Duplication of bio-chemical changes of Huntington's chorea by intrastriatal injections of glutamic and kainic acid. Nature 1976; 263: 517-9.

35 Beal MF, Marshall PE, Burd GD, Landis DMD, Martin JBB. Excitotoxin lesions do not mimic the alteration of somatostatin in Huntington disease. Brain Res 1985; 361: 135-45.

36 Beal MF, Kowall NW, Ellison DW, Swartz KJ, Mc Garvey U, Bird $\mathrm{ED}$, et al. Replication of the neurochemical characteristics of Huntington's disease by quinolinic acid. Nature 1986; 321: 16871.

37 Roberts R, Ahn A, Swartz KJ, Beal MF, DiFiglia M. Intrastriatal injections of quinolinic acid or kainic acid: differential patterns of cell survival and effects of data analysis on outcome. Exp Neurol 1993; 124: 274-82.

38 Qin ZH, Wang YM, Chase TN. Stimulation of $N$-methyl-Daspartate receptors induces apoptosis in rat brain. Brain Res 1996; 725: 166-76.

39 Qin ZH, Wang YM, Nakai M, Chase TN. Nuclear factor-kB contributes to excitotoxin-induced apoptosis in rat striatum. Mol Pharmacol 1998; 53: 33-42.

40 Liang ZQ, Wang XX, Wang YM, Chuang DW, DiFiglia M, Thomas $\mathrm{N}$, et al. Susceptibility of striatal neurons to excitotoxic injury correlates with basal levels of Bcl-2 and the induction of P53 and c-Myc immunoreactivity. Neurobiol Disease 2005; 20 : $562-73$.

41 Sanberg PR, Coyle JT. Scientific approaches to Huntington's disease. Crit Rev Clin Neurobiol 1984; 1: 1-44.

42 Qin ZH, Wang J, Gu ZL. Development of novel therapies for Huntington's disease: hope and challenge. Acta Pharmacol Sin 2005; 26: 129-42.

43 Ludolph AC, He F, Spencer PS, Hammerstad J, Sabri M. 3Nitroproprionic acid-exogenous animal neurotoxin and possible 
human striatal toxin. Can J Neurol Sci 1991; 18: 492-8.

44 Beal MF, Kowall NW, Ellison DW, Swartz KJ, Mc Garvey U, Bird $\mathrm{ED}$, et al. Replication of the neurochemical characteristics of Huntington's disease by quinolinic acid. Nature 1986; 321: 16871.

45 Hamilton BF, Gould DH. Nature and distribution of brain lesions in rats intoxicated with 3-nitropropionic acid: a type of hypoxic (energy deficient) brain damage. Acta Neuropathol 1987; 72: 286-97.

46 Guyot MC, Hantraye P, Dolan R, Palfi S, Maziere M, Brouillet E. Quantifiable bradykinesia, gait abnormalities and Huntington's disease-like striatal lesions in rats chronically treated with 3nitropropionic acid. Neuroscience 1997; 79: 45-56.

47 Beal MF, Brouillet E, Jenkins B, Ferrante RJ, Kowall NW, Miller $\mathrm{JM}$, et al. Neurochemical and histological characterization of the striatal excitotoxic lesions produced by the mitochondrial toxins 3-nitropropionic acid. J Neurosci 1993; 13: 1481-92.

48 Brouillet E, Guyot MC, Mittoux V, Altairac S, Conde F, Palfi S, et al. Partial inhibition of brain succinate deshydrogenase by 3 nitropropionic acid is sufficient to initiate striatal degeneration in rat. J Neurochem 1998; 70: 794-805.

49 Borlongan CV, Koutousis TK, Freeman TB, Cahill DW, Sanberg PR. Behavioral pathology induced by repreated systemic injections of 3-nitropropionic acid mimics the motoric symptoms of Huntington's disease. Brain Res 1995; 697: 254-7.

50 Borlongan CV, Koutousis TK, Randall TS, Freeman TB, Cahill DW, Sanberg PR. Systemic 3-nitropropionic acid: behavioral deficits and striatal damage in adult rats. Brain Res Bull 1995; 36 : 549-56.

51 Brouillet E, Jenkins B, Hyman B, Ferrante RJ, Kowall NW, Srivastava R, et al. Age-dependent vulnerability of the striatum to the mitochondrial toxin 3-nitropropionic acid. J Neurochem 1993; 60: 356-9.

52 Borlongan CV, Koutouzis TK, Sanberg PR. 3-Nitropropionic acid animal model and Huntington's disease. Neurosci Biobehav Rev 1997; 21: 289-93.

53 Mettler FA. Choreoathetosis and striopallidonigral necrosis due to sodium azide. Exp Neurol 1972; 34: 291-308.

54 Borlongan CV, Koutouzis TK, Cahill DW, Freeman TB, Sanberg PR. Behavioral pathology induced by repeated systemic injections of 3-nitropropionic acid mimics the motoric symptoms of Huntington's disease. Brain Res 1995; 697: 254-7.

55 Stober T, Wussow W, Schimrigk K. Bicaudate diameter - the most specific and simplified $\mathrm{CT}$ parameter in the diagnosis of Huntington's disease. Neuroradiology 1984; 26: 25-8.

56 Hantraye P, Riche D, Maziere M, Isacson O. An experimental primate model of Huntington's disease: anatomical and behavioural studies of unilateral excitotoxic lesions of the caudate-putamen in the baboon. Exp Neurol 1990; 108: 91-104.

57 Leavitt BR, Raamsdonk JM, Shehadeh J, Fernandes H, Murphy $\mathrm{Z}$, Graham RK, et al. Wild-type huntingtin protects neurons from excitotoxicity. J Neurochem 2006; 96: 1121-9.

58 Hickey MA, Chesselet MF. The use of transgenic and knock-in mice to study Huntington's disease. Cytogenet Genome Res 2003; 100: 276-86.

59 Sathasivam K, Hobbs C, Mangiarini L, Mahal A, Turmaine M, Doherty $\mathrm{P}$, et al. Transgenic models of Huntington's disease. Phil Trans R Soc Lond B 1999; 354: 963-9.
60 Mangiarini L, Sathasivam K, Seller M, Cozens B, Harper A, Hetherington $\mathrm{C}$, et al. Exon 1 of the HD gene with an expanded CAG repeat is sufficient to cause a progressive neurological phenotype in transgenic mice. Cell 1996; 87: 493-506.

61 Hurlbert MS, Zhou W, Wasmeier C, Kaddis FG, Hutton JC, Freed CR. Mice transgenic for an expanded $\mathrm{CAG}$ repeat in the Huntington's disease gene develop diabetes. Diabetes 1999; 48: 649-51

62 Davies SW, Turmaine M, Cozens BA, DiFiglia M, Sharp AH, Ross CA, et al. Formation of neuronal intranuclear inclusions underlies the neurological dysfunction in mice transgenic for the HD mutation. Cell 1997; 90: 537-48.

63 Turmaine M, Raza A, Mahal A, Mangiarini L, Bates GP, Davies SW. Nonapoptotic neurodegeneration in a transgenic mouse model of Huntington's disease. Proc Natl Acad Sci USA 2000; 97: 8093-7.

64 Hersch SM, Ferrante RJ. Translating therapies for Huntington's disease from genetic animal models to clinical trials. NeuroRx 2004; 3: 298-603.

65 Ross CA. Intranuclear neuronal inclusions: a common pathogenic mechanism for glutamine-repeat neurodegenerative diseases? Neuron 1997; 19: 1147-50.

66 DiFiglia M, Sapp E, Chase KO, Davies SW, Bates GP, Vonsattel JP, et al. Aggregation of huntingtin in neuronal intranuclear inclusions and dystrophic neurites in brain. Science 1997; 277: 1990-3.

67 Becher MW, Kotzuk JA, Sharp AH, Davies SW, Bates GP, Price $\mathrm{DL}$, et al. Intranuclear neuronal inclusions in Huntington's disease and dentatorubral and pallidoluysian atrophy: correlation between the density of inclusions and IT15 CAG triplet repeat length. Neurobiol Dis 1998; 4: 387-97.

68 Gourfinkel-An I, Cancel G, , Faucheux B, Hauw JJ, Trottier Y, et al. Neuronal distribution of intranuclear inclusions in Huntington's disease with adult onset. NeuroReport 1998; 9: 1823-6.

69 Goldberg YP, Kalchman MA, Metzler M, Nasir J, Zeisler J, Graham $\mathrm{R}$, et al. Absence of disease phenotype and intergenerational stability of the CAG repeat in transgenic mice expressing the human Huntington disease transcript. Hum Mol Genet 1996; 5: 177-85.

70 Reddy PH, Williams M, Charles V, Garrett L, Pike-Buchanan L, Whetsell WO Jr, et al. Behavioural abnormalities and selective neuronal loss in HD transgenic mice expressing mutated fulllength HD cDNA. Nat Genet 1998; 20: 198-202.

71 Hodgson JG, Agopyan N, Gutekunst CA, Leavitt BR, LePiane F, Singaraja R, et al. A YAC mouse model for Huntington's disease with full-length mutant huntingtin, cytoplasmic toxicity, and selective striatal neurodegeneration. Neuron 1999; 23: 181-92.

72 Jeremy M, Raamsdonk V, Murphy Z, Slow EJ, Leavitt BR, Hayden MR. Selective degeneration and nuclear localization of mutant huntingtin in the YAC128 mouse model of Huntington disease. Hum Mol Genet 2005; 24: 3823-35.

73 Tanaka Y, Igarashi S, Nakamura M, Gafni J, Torcassi C, Schilling $\mathrm{G}$, et al. Progressive phenotype and nuclear accumulation of an amino-terminal cleavage fragment in a transgenic mouse model with inducible expression of full-length mutant huntingtin. Neurobiol 2005; 14: 1-11.

74 Shelbourne PF, Killeen N, Hevner RF, Johnston HM, Tecott L, Lewandoski M, et al. A Huntington's disease CAG expansion at 
the murine Hdh locus is unstable and associated with behavioural abnormalities in mice. Hum Mol Genet 1999; 8: 763-74.

75 Lin CH, Tallaksen-Greene S, Chien WM, Cearley JA, Jackson WS, Crouse AB, et al. Neurological abnormalities in a knock-in mouse model of Huntington's disease. Hum Mol Genet 2001; 10: $137-44$.

76 Menalled LB, Sison JD, Wu Y, Olivieri M, Li XJ, Li H, et al. Early motor dysfunction and striosomal distribution of huntingtin microaggregates in Huntington's disease knock-in mice. J Neurosci 2002; 22: 8266-76.

77 Kirkwood SC, Su JL, Conneally P, Foroud T. Progression of symptoms in the early and middle stages of Huntington disease. Arch Neurol 2001; 58: 273-8.

78 Menalled LB, Chesselet MF. Mouse models of Huntington's disease. Trends Pharmacol Sci 2002; 23: 32-9.

79 Kennedy L, Shelbourne PF. Dramatic mutation instability in HD mouse striatum: does polyglutamine load contribute to cell-specific vulnerability in Huntington's disease? Hum Mol Genet 2000; 9: 2539-44.

80 Duyao MP, Auerbach AB, Ryan A, Persichetti F, Barnes GT, $\mathrm{McNeil} \mathrm{SM}$, et al. Inactivation of the mouse Huntington's disease gene homolog Hdh. Science 1995; 269: 407-10.

81 Nasir J, Floresco SB, O'Kusky JR, Diewert VM, Richman JM, Zeisler J, et al. Targeted disruption of the Huntington's disease gene results in embryonic lethality and behavioral and morphological changes in heterozygotes. Cell 1995; 81: 811-23.

82 Zeitlin S, Liu JP, Chapman DL, Papaioannou VE, Efstratiadis A. Increased apoptosis and early embryonic lethality in mice nullizygous for the Huntington's disease gene homologue. Nat Genet 1995; 11: 155-63.

83 White JK, Auerbach W, Duyao MP, Vonsattel JP, Gusella JF, Joyner AL, et al. Huntingtin is required for neurogenesis and is not impaired by the Huntington's disease CAG expansion. Nat Genet 1997; 17: 404-10.

84 Clabough EB, Zeitlin SO. Deletion of the triplet repeat encoding polyglutamine within the mouse Huntington's disease gene results in subtle behavioral/motor phenotypes in vivo and elevated levels of ATP with cellular senescence in vitro. Hum Mol Genet 2006; 15: 607-23.

85 Senut MC, Suhr ST, Kaspar B, Gage FH. Intraneuronal aggregate formation and cell death after viral expression of expanded polyglutamine tracts in the adult rat brain. J Neurosci 2000; 20 : 219-29.

86 Morley JF, Brignull HR, Weyers JJ, Morimoto RI. The threshold for polyglutamine-expansion protein aggregation and cellular toxicity is dynamic and influenced by aging in Caenorhabditis elegans. Proc Natl Acad Sci USA 2002; 99: 10417-22.

87 de Almeida LP, Ross CA, Zala D, Aebischer P, Deglon N. Lentiviral-mediated delivery of mutant huntingtin in the striatum of rats induces a selective neuropathology modulated by polyglutamine repeat size huntingtin expression levels and protein length. J Neurosci 2002; 22: 3473-83.

88 Rubin GM, Yandell MD, Wortman JR, Gabor Miklos GL, Nelson $\mathrm{CR}$, et al. Comparative genomics of the eukaryotes. Science 2000; 287: 2204-15.

89 Reiter LT, Potocki L, Chien S, Gribskov M, Bier E. A systematic analysis of human disease-associated gene sequences in Drosophila melanogaster. Genome Res 2001; 11: 1114-25.
90 Li Z, Karlovich CA, Fish MP, Scott MP, Myers RM. A putative drosophila homolog of the Huntington's disease gene. Hum Mol Genet 1999; 8: 1807-15.

91 Marsh JL, Pallos J, Thompson LM. Fly models of Huntington's disease. Hum Mol Genet 2003; 12: R187-R193.

92 Brand AH, Perrimon N. Targeted gene expression as a means of altering cell fates and generating dominant phenotypes. Development 1993; 118: 401-15.

93 Brand AH, Dormand EL. The GAL4 system as a tool for unravelling the mysteries of the Drosophila nervous system. Curr Opin Neurobiol 1995; 5: 572-8.

94 Steffan JS, Bodai L, Pallos J, Poelman M, McCampbell A, Apostol $\mathrm{BL}$, et al. Histone deacetylase inhibitors arrest polyglutaminedependent neurodegeneration in Drosophila. Nature 2001; 413: 739-43.

95 Jackson GR, Salecker I, Dong X, Yao X, Arnheim N, Faber PW, et al. Polyglutamine-expanded human huntingtin transgenes induce degeneration of Drosophila Bonini, NM. Suppression of polyglutamine-mediated neurodegene-photoreceptor neurons. Neuron 1999; 21: 633-42.

96 Parker JA, Connolly JB, Wellington C, Hayden M, Dausset J, Neri C. Expanded polyglutamines in Caenorhabditis elegans cause axonal abnormalities and severe dysfunction of PLM mechano-sensory neurons without cell death. Proc Natl Acad Sci USA 2001; 98: 13 318-23.

97 Chalfie M. The mec-3 gene of Caenorhabditis elegans requires its own product for maintained expression and is expressed in three neuronal cell types. Genes Dev 1989; 3: 1823-33.

98 The $C$ elegans Sequencing Consortium. Genome sequence of the nematode $C$ elegans: a platform for investigating biology. Science 1998; 282: 2012-8.

99 Faber PW, Alter JR, MacDonald ME, Hart AC. Polyglutaminemediated dysfunction and apoptotic death of a Caenorhabditis elegans sensory neuron. Proc Natl Acad Sci USA 1999; 96: 17984.

100 Marsh JL, Walker H, Theisen H, Zhu YZ, Fielder T, Purcell J, et al. Expanded polyglutamine peptides alone are intrinsically cytotoxic and cause neurodegeneration in Drosophila. Hum Mol Genet 2000; 9: 13-25.

101 Moore H, Greenwell PW, Liu CP, Arnheim N, Petes TD. Triplet repeats form secondary structures that escape DNA repair in yeast. Proc Natl Acad Sci USA 1999; 96: 1504-9.

102 Schweitzer JK, Livingston DM. Destabilization of CAG trinucleotide repeat tracts by mismatch repair mutations in yeast. Hum Mol Genet 1997; 6: 349-55.

103 Kazantsev A, Preisinger E, Dranovsky A, Goldgaber D, Housman D. Insoluble detergent-resistant aggregates form between pathological and nonpathological lengths of polyglutamine in mammalian cells. Proc Natl Acad Sci USA 1999; 96: 11404-9.

104 Krobitsch S, Lindquist S. Aggregation of huntingtin in yeast varies with the length of the polyglutamine expansion and the expression of chaperone proteins. Proc Natl Acad Sci USA 2000; 97: 1589-94.

105 Burke JR, Enghild JJ, Martin ME, Jou YS, Myers RM, Roses AD, et al. Huntingtin and DRPLA proteins selectively interact with the enzyme GAPDH. Nat Med 1996; 2: 347-50.

106 Li SH, Hosseini SH, Gutekunst CA, Hersch SM, Ferrante RJ, Li XJ. A human HAP1 homologue. Cloning, expression, and 
interaction with huntingtin. J Biol Chem 1998; 273: 19 220-7.

107 Kim M, Lee HS, LaForet G, McIntyre C, Martin EJ, Chang P, et al. Mutant huntingtin expression in clonal striatal cells: dissociation of inclusion formation and neuronal survival by caspase inhibition. J Neurosci 1999; 19: 964-73.

108 Rigamonti D, Bauer JH, De-Fraja C, Conti L, Sipione S, Sciorati $\mathrm{C}$, et al. Wild-type huntingtin protects from apoptosis upstream of caspase-3. J Neurosci 2000; 20: 3705-13.

109 Sipione S, Rigamonti D, Valenza M, Zuccato C, Conti L, Pritchard J, et al. Early transcriptional profiles in huntingtininducible striatal cells by microarray analyses. Hum Mol Genet 2002; 17: 1953-65.

110 Wyttenbach A, Swartz J, Kita H, Thykjaer T, Carmichael J, Bradley J, et al. Polyglutamine expansions cause decreased CRE-mediated transcription and early gene expression changes prior to cell death in an inducible cell model of Huntington's disease. Hum Mol Genet 2001; 10: 1829-45.

111 Qin ZH, Wang Y, Kegel KB, Kazantsev A, Apostol BL, Thompson LM, et al. Autophagy regulates the processing of amino terminal huntingtin fragments. Hum Mol Genet 2003; 24: 3231-44.

112 Ravikumar B, Vacher C, Berger Z, Davies JE, Luo S, Oroz LG, et al. Inhibition of mTOR induces autophagy and reduces toxicity of polyglutamine expansions in fly and mouse models of Huntington disease. Nat Genet 2004; 36: 585-95.

113 Hersch SM, Ferrante RJ. Translating therapies for Huntington's disease from genetic animal models to clinical trials. NeuroRx 2004; 1: 298-306.

114 Young AB. Huntingtin in health and disease. J Clin Invest 2003; 111: 299-302.

115 Sittler A, Lurz R, Lueder G, Priller J, Lehrach H, Hayer-Hartl MK, et al. Geldanamycin activates a heat shock response and inhibits huntingtin aggregation in a cell culture model of Huntington's disease. Hum Mol Genet 2001; 10: 1307-15.

116 Heemskerk J, Tobin AJ, Bain LJ. Teaching old drugs new tricks.
Meeting of the neurodegeneration drug screening consortium. Trends Neurosci 2002; 25: 494-6.

117 Heiser V, Scherzinger E, Boeddrich A, Nordhoff E, Lurz R. Schugardt $\mathrm{N}$, et al. Inhibition of huntingtin fibrillogenesis by specific antibodies and small molecules: implications for Huntington's disease therapy. Proc Natl Acad Sci USA 2000; 97: 6739-44.

118 Apostol BL, Kazantsev A, Raffioni S, Illes K, Pallos J, Bodai L, et al. A cell-based assay for aggregation inhibitors as therapeutics of polyglutamine-repeat disease and validation in Drosophila. Proc Natl Acad Sci USA 2003; 100: 5950-5.

119 Hickey MA, Gallant K, Gross GG, Levine MS, Chesselet MF. Early behavioral deficits in R6/2 mice suitable for use in preclinical drug testing. Neurobiol Dis 2005; 20: 1-11.

120 Kazantsev A, Walker H, Slepko N, Bear JE, Preisinger E, Steffan JS, et al. A bivalent Huntingtin binding peptide suppresses polyglutamine aggregation and pathogenesis in Drosophila. Nat Genet 2002; 30: 367-76.

121 Apostol BL, Kazantsev A, Raffioni S, Illes K, Pallos J, Bodai L, et al. A cell-based assay for aggregation inhibitors as therapeutics of polyglutamine-repeat disease and validation in Drosophila. Proc Natl Acad Sci USA 2003; 100: 5950-5.

122 Dedeoglu A, Kubilus JK, Jeitner TM, Matson SA, Bogdanov M, Kowall NW, et al. Therapeutic effects of cystamine in a murine model of Huntington's disease. J Neurosci 2002; 22: 8942-50.

123 Karpuj MV, Becher MW, Springer JE, Chabas D, Youssef S, Pedotti R, et al. Prolonged survival and decreased abnormal movements in transgenic model of Huntington disease, with administration of the transglutaminase inhibitor cystamine. Nat Med 2002; 8: 143-9.

124 Sanchez I, Mahlke C, Yuan J. Pivotal role of oligomerization in expanded polyglutamine neurodegenerative disorders. $\mathrm{Na}$ ture $2003 ; 421$ : 373-9. 